\title{
Perioperative enhancement for CHD patients
}

\author{
Received: 14 October 2016; Accepted: 21 October 2016; First published online: 6 February 2017
}

To the Editor,

We applaud Wernovsky et al for sharing what we strongly support as excellent guidelines for standardised testing and coordinated surveillance of patients with complex CHD. ${ }^{1}$ In the United States of America, there are currently more adults than children living with $\mathrm{CHD}$, and projections indicate that this population will continue to grow. ${ }^{2}$

CHD patients have improved life expectancy, higher healthcare utilisation rates, ${ }^{3}$ and increasingly require elective or emergent non-cardiac surgical, radiological, obstetric, and/or procedural care under anaesthesia. These patients have a higher risk of mortality compared with patients without $\mathrm{CHD}, 4,5$ and consequently carry with them lifetime complex medical and social issues that require multidisciplinary care.

Therefore, a perioperative care plan including consultation with an anaesthesiologist, discussion of unique patient characteristics that portend risk, anaesthetic technique, appropriate testing, and procedure location should be included in the "roadmap" for each patient. This type of patient-centred, interdisciplinary, coordinated care at our institution is implemented by the Perioperative Enhancement Team, whose projects to date have addressed patients with anaemia, diabetes, malnutrition, senior health, and chronic pain. ${ }^{6,7}$ Motivated by the recommendations of Wernovsky et al, Perioperative Enhancement Team will now go forward to develop a programme to address the unique and important perioperative challenges of patients with $\mathrm{CHD}$.

\section{Acknowledgement}

None.

\section{Financial Support}

None.

\section{Conflicts of Interest}

None.

\author{
Elizabeth B. Malinzak, Solomon Aronson, \\ Ankeet D. Udani \\ Department of Anesthesiology \\ Duke University School of Medicine, Durbam \\ North Carolina, United States of America
}

\section{References}

1. Wernovsky G, Lihn SL, Olen MM. Creating a lesion-specific "roadmap" for ambulatory care following surgery for complex congenital cardiac disease. Cardiol Young 2016; 1-15.

2. Cannesson M, Earing MG, Collange V, et al. Anesthesia for noncardiac surgery in adults with congenital heart disease. Anesthesiology 2009; 111: 432-440.

3. Mackie AS, Pilote L, Ionescu-Ittu R, et al. Health care resource utilization in adults with congenital heart disease. Am J Cardiol 2007; 99: 839-843

4. Faraoni D, Zurakowski D, Vo D, et al. Post-operative outcomes in children with and without congenital heart disease undergoing noncardiac surgery. J Am Coll Cardiol 2016; 67: 793-801.

5. Maxwell BG, Wong JK, Kin C, et al. Perioperative outcomes of major noncardiac surgery in adults with congenital heart disease. Anesthesiology 2013; 119: 762-769.

6. Aronson S, Attarian DE. The future of perioperative medicine. ASA Monit 2016; 80: 16-18.

7. Guinn NR, Guercio JR, Hopkins TJ, et al. How do we develop and implement a preoperative anemia clinic designed to improve perioperative outcomes and reduce cost? Transfusion 2016; 56: 297-303. 